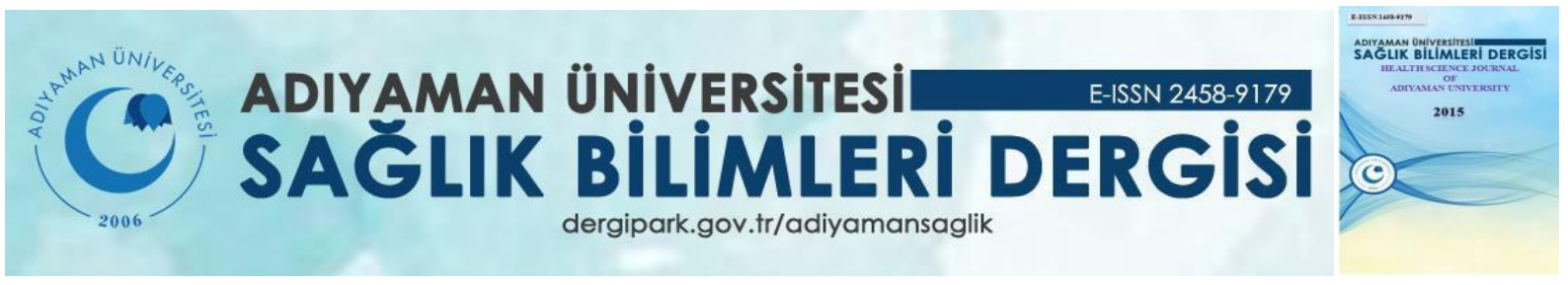

Araştırma/Research

\title{
Geriatri Stajı Yapma Durumunun Son Sınıf Fizyoterapi Öğrencilerinin Yaşlı Ayrımcılığına İlişkin Tutumları Üzerine Etkisinin Belirlenmesi
}

\author{
Tahir KESKİN ${ }^{1}$, Mesut ERGAN² ${ }^{2}$, Zeliha BAŞKURT ${ }^{3}$, Ferdi BAŞKURT ${ }^{4}$
}

1,2,3,4 Süleyman Demirel Üniversitesi Sağlık Bilimleri Fakültesi Fizyoterapi ve Rehabilitasyon Bölümü, Isparta, TÜRKIYE

\section{ÖZ}

Amaç: Yaşlı ayrımcılığı bir kişiye sadece yaşı nedeniyle gösterilen farklı tavır, önyargı, davranış ve eylemleri içinde barındıran çok boyutlu bir terimdir. Çalışmamızın amacı geriatri stajı yapan ve henüz yapmamış olan fizyoterapi öğrencileri arasında yaşlı ayrımcılığı tutumu açısından farklılık olup olmadığını belirlemektir.

Yöntem: Çalışmamız tanımlayıcı nitelikte olup; Fizyoterapi ve Rehabilitasyon Bölümü 4. sınıfta eğitim gören ve Klinik Uygulama dersi kapsamında geriatri stajı yapmış olan (50) ve henüz staja çıkmayan (44) toplam 94 öğrenci ile yapılmıştır. Çalışmanın verileri araştırmacılar tarafından hazırlanan Kişisel Bilgi Formu ve Yaşı Ayrımcılığı Tutum Ölçeği (YATÖ) ile toplanmıştır.

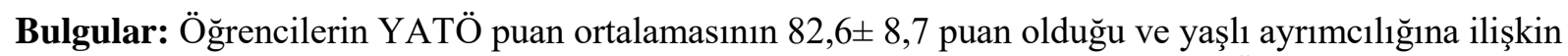
tutumlarının olumlu olduğu belirlenmiştir. Geriatri stajı yapan öğrencilerin YATÖ toplam puanlarının, yapmayanlara göre daha yüksek olduğu fakat bu farkın istatistiksel olarak anlamlı olmadığı saptanmıştır ( $>0,05)$. Ayrıca yaşamının en uzun süresini Köy/Kasaba'da geçirenlerin, şimdiye kadar 65 yaş üstü bireylerle beraber yaşamayan kişilerin ve kardeş sayısı 3 ve altında olanların YATÖ puanları daha yüksek bulunmuştur fakat bu farklar istatistiksel olarak anlamlı değildir $(\mathrm{p}<0,05)$.

Sonuç: Fizyoterapi öğrencilerinin yaşlı ayrımcılığına ilişkin tutumlarının olumlu olduğu, kısa süre yaşlı bireylerle çalışmanın yaşlı ayrımcılığına ilişkin tutumları olumlu anlamda etkilediği belirlenmiştir. Klinik uygulamalarda öğrencilerle yaşlı bireylerin etkileşiminin artırılmasının, öğrencilerin yaşlılara yönelik tutumlarını olumlu anlamda etkileyeceği düşünülmektedir.

Anahtar Sözcükler: Yaşlı Ayrımcılı̆̆ı; Klinik Uygulama; Geriatri Stajı; Fizyoterapi öğrencileri.

\begin{tabular}{l}
\hline Yazışmadan Sorumlu Yazar: \\
Tahir KESKIN \\
Adres: Süleyman Demirel Üniversitesi Sağlık Bilimleri \\
Fakültesi Fizyoterapi ve Rehabilitasyon Bölümü, Çünür, \\
ISPARTA, TÜRKIYE \\
Telefon: +905309219261 \\
e-mail: tahirkeskin2323@ gmail.com \\
ORCID: 0000-0002-9237-3300
\end{tabular}

Doi: 10.30569.adiyamansaglik.562720

Geliş Tarihi : 10.05.2019

Kabul Tarihi : 26.11.2019

Atıf Gösterimi/How to Cite: Keskin T, Ergan M, Başkurt Z, Başkurt F. Geriatri Staj1 Yapma Durumunun Son Sınıf Fizyoterapi Öğrencilerinin Yaşlı Ayrımcılığına İlişkin Tutumları Üzerine Etkisinin Belirlenmesi. Adıyaman Üni. Sağlık Bilimleri Derg. 2019; 5(3); 1757-1766. doi: 10.30569.adiyamansaglik.562720. 


\title{
Determination of The Effect of Senior Physiotherapy Students' Practicing Geriatric Internship on Ageizm Attitudes
}

\begin{abstract}
Aim: Ageizm is a multidimensional term that involves different attitudes, prejudices, behaviors and actions that are displayed to a person due to his or her age. The aim of our study is to determine whether there is a difference in the attitude of elderly discrimination according to the status of performing geriatric internship among physiotherapy students.
\end{abstract}

Method: A descriptive study was carried out with 94 senior physical therapy students taking the clinical practice course. The data of the study were collected by personal information form prepared by the researchers and ageism attitude scale.

Results:The average score of the students was $82.6 \pm 8.7$ points and the attitudes towards ageizm were found to be positive. It was found that the total scores of the students who had undergone geriatric internship were higher than those who did not, but this difference was not statistically significant ( $>$ > 0.05). In addition, the percentage of those who lived in Village / Town for the longest period of their life, those who did not live with the individuals above 65 years old and those who had 3 or under the number of siblings had higher scores of ageizm attitude total scores, but these differences were not statistically significant ( $p>0.05)$.

Conclusion: It was determined that the attitudes of the physiotherapy students towards the ageizm were positive, and working with older people in a short time positively affected the attitudes towards elderly discrimination.It is thought that increasing the interaction of students with elderly people in clinical applications will positively affect students' attitudes towards elderly people.

Keywords: Elderly Discrimination; Clinical Practice; Geriatric Internship; Physiotherapy students

\section{GİRIŞ}

Son yıllarda dünya genelinde doğum oranlarında görülen azalma, sağlık ve teknoloji alanlarındaki gelişmeler, kronik hastalıkların tedavisinde kaydedilen ilerlemeler ortalama yaşam süresinin uzamasına ve yaşlı nüfusun toplum içinde artış göstermesine neden olmaktadır. Bütün ülkelerin sağlık ve sosyal sistemleri bu demografik değişime ayak uydurma konusunda 
büyük zorluklar yaşamaktadır (1). Yaşlı nüfus oranı 2016 yılında Dünya nüfusunun yaklaşık \%8,7'sini oluşturmuştur. Bu oranın 2050 yılında \%22'ye çıkması beklenmektedir. Ülkemizdeki oranlara bakıldığında ise yaşlı nüfusun toplam nüfus içindeki oranı ise \%8,5 olup, 2023 yılında yaklaşık \%10,2 olacağı öngörülmektedir $(2,3)$.

Yaşlı nüfusun toplum içinde artmasıyla hastanelere başvuran yaşlı birey sayısı da artmakta, dolayısıyla yaşlı bireylere hizmet verilen tüm alanlarda bazı güçlüklerle karşı karşıya kalınmaktadır. Bu güçlüklerden biri de yaşlı ayrımcılığıdır (4). Literatürde yaşlı ayrımcılığı terimini ilk olarak kullanan kişi olan Robert Butler, yaşlı ayrımcılığını; "insanlara yönelik bir ayrımcılık, ırk ayrımcılığı ve cinsiyet ayrımcılığı gibi eyleme dönüşebilen bir ideoloji türü” olarak tanımlamıştır (5). Yapılan çalışmalar yaşlı ayrımcılığının en sık aile yaşamı, sosyal yaşam, cinsel yaşam ve sağlık bakım hizmetlerinde olduğunu ve bu ayrımcılığa yaşlılarda görülen fiziksel, zihinsel ve psikolojik değişimlerin neden olabileceği belirtilmektedir $(6,7)$. Yaşlı ayrımcılığı ile ilgili yapılan çalışmalar yaşlılara yönelik hem olumlu hem de olumsuz tutumlar sergilendiğini göstermektedir. Yaşlılara yönelik olumlu davranışlar yaşlılara yapılan hizmetin kalitesini arttırırken, olumsuz davranışlar ise düşürmektedir $(8,9)$.

Yaşla birlikte meydana gelen fizyolojik değişikliklere bağlı olarak gelişen problemler ve kronik hastalıklar yaşlıların sağlık hizmetlerine olan ihtiyacını arttırmaktadır. Dolayısıyla sağlık profesyonelleri yaşlılarla daha fazla çalışma olanağı bulmaktadır. Sağlık çalışanlarının yaşlanma ve yaşlı hakkındaki yanlış inanışları, olumsuz tutumları, yaşlılara sunulan hizmetlerin etkinliğinin ve kalitesinin azalmasına neden olabilmektedir (10).

Klinik deneyimler yoluyla yaşlı yetişkinlerin tedaviye alınması öğrencilerdeki olumsuz tutumları değiştirmek ve gerontolojiye ilgilerini artırmak için kullanılan yaygın yaklaşımlardandır. Hastalarla temasa geçmenin sağlıkla ilgili bölümlerde öğrenim gören öğrenciler tarafından öz güven, klinik alanda hevesli olma ve gelecekteki profesyonel sorumluluklarının farkındalığı için değerli bir öğrenme deneyimi olduğu belirlenmiştir (11). Fizyoterapistlerin yaşlı bireylere verdiği sağlık hizmeti sadece yaşlı bakım merkezleri ya da huzurevleriyle sınırlı değildir. Görev yapılan bütün bölümlerde hizmet verilen 65 yaş üstü bireyler geriatrik rehabilitasyon kapsamında olduğu için, fizyoterapi, sağlık disiplinleri içinde yaşlı bireylerle en sık etkileşimde bulunan bölümlerden biri olarak kabul edilebilir. Bu nedenle fizyoterapistlerin yaşlı ayrımcılığına ilişkin tutumlarının yaşı bireylere verilen hizmetin kalitesini etkileyeceği düşünülmektedir. Bu nedenle çalışmamızın amacı geriatri stajı yapan ve 
yapmayan fizyoterapist adaylarının yaşlılara yönelik tutumlarında farklılık olup olmadığını belirlemektir.

\section{YÖNTEM}

Geriatri stajı yapma durumunun son sınıf fizyoterapi öğrencilerinin yaşlı ayrımcılığına ilişkin tutumları üzerine etkisini belirlemek amacıyla yapmış olduğumuz çalışmamıza Süleyman Demirel Üniversitesi Sağlık Bilimleri Fakültesi Fizyoterapi ve Rehabilitasyon Bölümü 4. sınıfında öğrenim gören 94 öğrenci gönüllülük esasıyla dahil edilmiştir. Çalışma öncesinde çalışmaya katılan öğrencilere çalışmanın amaç ve prosedürleri açıklanmış ve onamları alınmıştır. Öğrenciler Klinik Uygulama Dersi kapsamında geriatrik rehabilitasyon prensiplerini uygulamalı olarak öğrenme firsatı buldukları staj uygulaması olan 4 haftalık geriatri stajını yapma durumuna göre 2 gruba ayrılmıştır. Geriatri stajını tamamlayan öğrenciler 1. grubu, henüz geriatri stajı yapmayanlar ise 2. grubu oluşturmuştur. Son sınıf öğrencisi olmak ve çalışmaya katılmaya gönüllü olmak dâhil edilme kriterini oluştururken; çalışmaya katılmayı istemeyen kişiler çalışma dışında tutulmuştur.

Veri Toplama Araçları: Araştırmanın verileri, literatür taraması yapılarak araştırmacılar tarafından geliştirilen “Kişisel Bilgi Formu” ve "Yaşlı Ayrımcılığı Tutum Ölçeği” kullanılarak toplanmıştır.

Kişisel Bilgi Formu: $\mathrm{Bu}$ bölümde öğrencilerin yaş, cinsiyet ve eğitim durumu gibi sosyodemografik özellikleri ve aile tipi, kardeş sayısı, doğum yeri, uzun süre yaşanılan yer, aynı evde yaşlılarla yaşama durumu ve süresi gibi yaşlı ayrımcılığına ilişkin tutumları etkileyebilecek değişkenler sorgulanmıştır.

Yaşlı Ayrımcılığı Tutum Ölçeği (YATÖ): Vefikuluçay tarafından 2008 yılında geliştirilmiş, geçerlik ve güvenirlik çalışması yapılmış, 23 maddeden ve üç boyuttan (yaşlının yaşamını sınırlama, yaşlıya yönelik olumlu ayrımcılık, yaşlıya yönelik olumsuz ayrımcılık) oluşan 5'li likert tip bir ölçektir. Ölçekte olumlu ve olumsuz tutum maddeleri bulunmaktadır. Olumlu ifadelere verilen yanıtlara "tamamen katılıyorum" için 5, "katılıyorum" için 4, "kararsızım" için 3, "katılmıyorum" için 2, "kesinlikle katılmıyorum" için 1 puan verilir. Olumsuz ifadelere verilen yanıtlarda ise tam tersi puanlama yapılır. Ölçekten alınabilecek en düşük puan 23, en yüksek puan ise 115'tir. Alınan puanların yüksek olması yaşlı ayrımcılığına ilişkin tutumların olumlu olduğunu göstermektedir (4). 
İstatistiksel Analiz: Katılımcılardan elde edilen tüm verilerin istatistiksel analizleri IBM SPSS

Statistics versiyon 20.0 programı ile yapılmıştır. Öğrencilerin sosyodemografik özellikleri standart sapmalar ve yüzde ve oranlarla tanımlanmıştır. Bazı değişkenlere göre YATÖ puanları değerlendirilmesinde ise veriler normal dağılım gösterdiği için bağımsız gruplarda t testi ve One Way Anova testleri kullanılmıştır. İstatistiksel anlamlılık düzeyi $\mathrm{p}<0,05$ olarak kabul edilmiştir.

\section{BULGULAR}

Çalışmaya katılan öğrencilerin \%72,3 (68)'ü kadın, \%27,7 (26)'si ise erkek olup, yaş

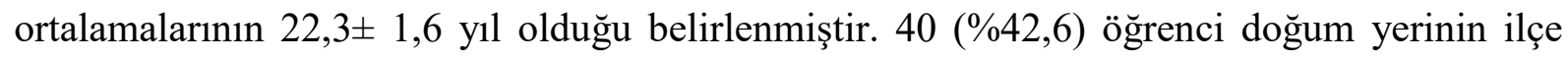
merkezi olduğunu, 31(\%33,3) öğrenci ise yaşamının büyük kısmını büyükşsehirde geçirdiği belirtmiştir. Öğrencilerinin \%80,9’u çekirdek aile yapısına sahip olup, \%72,3'ünün üç veya daha az kardeşi bulunmaktadır. YATÖ puanları kadınlarda, şehir merkezinde doğan kişilerde ve kardeş sayısı 3 'ün altında olan kişilerde yüksek bulunmuştur fakat bu farklılıklar istatistiksel olarak anlamlı değildir ( $\mathrm{p}>0,05)$ (Tablo 1).

Tablo 1: Öğrencilerin Sosyodemografik Özelliklerine göre YATÖ Puanları değişimi

\begin{tabular}{|c|c|c|c|c|c|}
\hline & $\begin{array}{c}\text { Geriatri stajı } \\
\text { yapanlar } \\
(\mathrm{n}=\mathbf{5 0}, \% \mathbf{5 3 , 2})\end{array}$ & $\begin{array}{l}\text { Geriatri stajı } \\
\text { yapmayanlar } \\
(n=44, \% 46,8)\end{array}$ & $\mathbf{p}$ & $\begin{array}{l}\text { Tüm gruplar } \\
(n=95, \% 100)\end{array}$ & YATÖ puanı \\
\hline \multicolumn{6}{|l|}{ Cinsiyet (n /\%) } \\
\hline Erkek & $15(30)$ & $11(25)$ & $0,593 \dagger$ & $26(27,7)$ & $82,4 \pm 9,2$ \\
\hline Kadın & $35(70)$ & $33(75)$ & & $68(72,3)$ & $82,9 \pm 7,3$ \\
\hline \multicolumn{6}{|l|}{ Doğum yeri(n /\%) } \\
\hline Köy- kasaba & $4(8)$ & $8(18,2)$ & & $12(12,8)$ & $80,2 \pm 7,7$ \\
\hline İlçe & $22(44)$ & $18(40,9)$ & $0,369 \ddagger$ & $40(42,6)$ & $83,7 \pm 8,9$ \\
\hline Şehir & $12(24)$ & $8(18,2)$ & & $20(21,3)$ & $84,8 \pm 7,7$ \\
\hline Büyükşehir & $12(24)$ & $10(22,7)$ & & $22(23,4)$ & $79,6 \pm 9,5$ \\
\hline \multicolumn{6}{|l|}{$\begin{array}{c}\text { Uzun süre yaşanan } \\
\text { yer }(\mathrm{n} / \%)\end{array}$} \\
\hline Köy- kasaba & $10(20)$ & $6(13,6)$ & $0606+$ & $16(16,1)$ & $83,3 \pm 9,4$ \\
\hline İlçe & $12(24)$ & $17(38,6)$ & $0,000 \div$ & $29(31,2)$ & $82,5 \pm 10,1$ \\
\hline Şehir & $10(20)$ & $8(18,2)$ & & $18(19,4)$ & $82,0 \pm 7,3$ \\
\hline Büyükşehir & $18(36)$ & $13(29,5)$ & & $31(33,3)$ & $82,6 \pm 8,3$ \\
\hline
\end{tabular}




\begin{tabular}{c|ccccc}
\hline $\begin{array}{c}\text { Kardeş sayısı (n } \\
\text { /\%) }\end{array}$ & & & & \\
3 ve altı & $38(76)$ & $30(68,2)$ & $0,727 \dagger$ & $68(72,3)$ & $83,1 \pm 7,7$ \\
4 ve üzeri & $12(24)$ & $14(31,8)$ & & $26(27,7)$ & $81,0 \pm 11,2$ \\
\cline { 1 - 1 } Aile tipi (n /\%) & & & & \\
Çekirdek aile & $42(84)$ & $34(77,3)$ & $0,545 \dagger$ & $76(80,8)$ & $82,5 \pm 8,8$ \\
Geniş aile & $8(16)$ & $10(22,7)$ & & $18(19,2)$ & $82,3 \pm 8,8$ \\
& & & & & \\
\hline
\end{tabular}

$\uparrow:$ Bağımsız gruplarda $t$ testi, $¥$ : One way anova testi

$60(\% 63,9)$ öğrenci yaşlılarla birlikte aynı evde yaşamamış olup 5 yıl ve üzeri süre boyunca yaşlılarla aynı evde yaşayanların oranı \%18,1dir. 2 ile 4 yıl arasında yaşlılarla birlikte yaşayan kişilerde YATÖ puanları daha yüksek bulunmuştur fakat bu fark istatistiksel olarak anlamlı değildir ( $\mathrm{p}>0,05)$ (Tablo 2).

Tablo 2: Yaşlı ayrımcılığına ilişkin tutumları etkileyebilecek bazı değişkenlere göre YATÖ Puanları değişimi

\begin{tabular}{|c|c|c|c|c|}
\hline $\begin{array}{c}\text { Geriatri stajı } \\
\text { yapanlar } \\
(\mathrm{n}=\mathbf{5 0}, \% \mathbf{5 3 , 2})\end{array}$ & 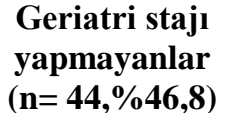 & $\mathbf{p}$ & $\begin{array}{l}\text { Tüm gruplar } \\
(n=95, \% 100)\end{array}$ & YATÖ puanı \\
\hline
\end{tabular}

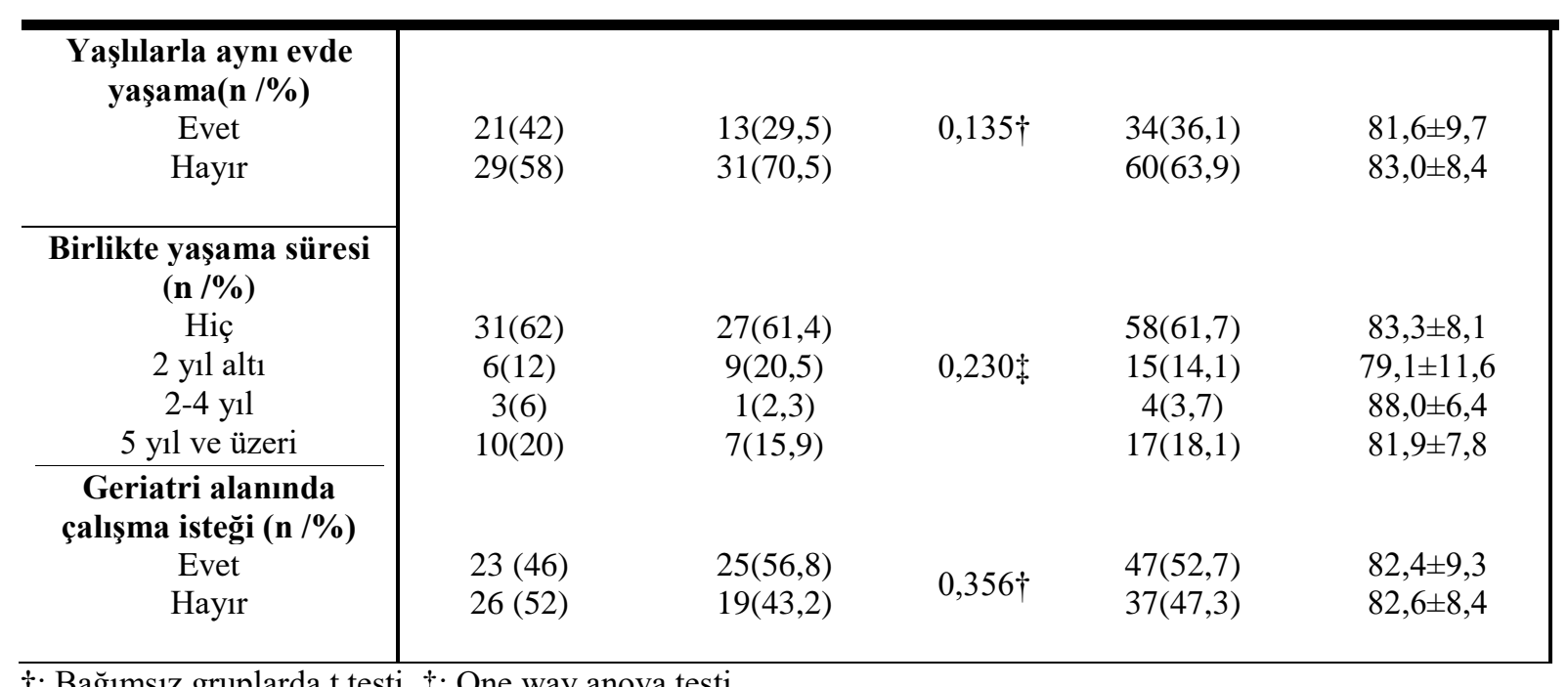

$\dagger$ : Bağımsız gruplarda t testi, + : One way anova testi

Öğrencilerin \%52,7'si mezun olduktan sonra yaşlılarla çalışmayı istediğini bildirmiş ve en yüksek oranla bunun nedeninin "Yaşl1ların fiziksel ve psikolojik olarak desteğe ihtiyaç duyması" olduğunu belirtmiştir. Mezuniyet sonrası yaşlılarla çalışmak istemeyenler ise $(\% 47,3)$ yaşlılarla çalışmayı istememe nedeni olarak "Sürekli yaşlı insanlarla çalışmanın tükenmişliğe yol açması" olduğunu belirtmiştir. 


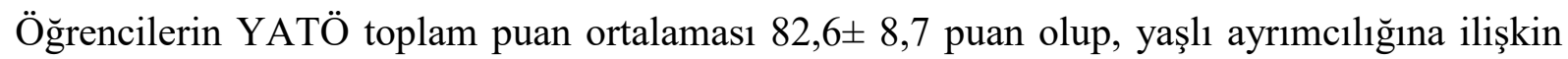
tutumlarının olumlu olduğu belirlenmiştir. Geriatri stajı yapan öğrencilerin YATÖ toplam puanlarının, yapmayanlara göre daha yüksek olduğu fakat bu farkın istatistiksel olarak anlamlı olmadığg ( $>0$,05) saptanmıştır. YATÖ alt boyutlarından yaşlının yaşamını sınırlama, yaşlıya yönelik olumlu ayrımcılık ve yaşlıya yönelik olumsuz ayrımcılık alt boyut puan ortalamalarının sırasıyla; 35,1 $\pm 5,0,30,2 \pm 4,3,17,0 \pm 3,1$ puan olduğu ve YATÖ alt boyut puanları açısından geriatri stajı yapan ve yapmayan öğrenciler arasında anlamlı bir farklılık olmadığ edilmiştir ( $>0,05)$ (Tablo 3).

Tablo 3. Geriatri stajı yapma durumuna göre öğrencilerin YATÖ toplam ve alt boyut puan ortalamalar1

\begin{tabular}{ccccc}
\cline { 2 - 5 } & $\begin{array}{c}\text { Geriatri stajı } \\
\text { yapanlar } \\
\text { mean } \pm \text { SD }\end{array}$ & $\begin{array}{c}\text { Geriatri stajı } \\
\text { yapmayanlar } \\
\text { mean } \pm \text { SD }\end{array}$ & p $\dagger$ & $\begin{array}{c}\text { Tüm gruplar } \\
\text { mean } \pm \text { SD }\end{array}$ \\
\hline $\begin{array}{c}\text { Yaşlının Yaşamını Sınırlama } \\
\text { Yaşlıya Yönelik Olumlu } \\
\text { Ayrımcılı }\end{array}$ & $35,6 \pm 5,4$ & $34,6 \pm 4,5$ & 0,333 & $35,1 \pm 5,0$ \\
$\begin{array}{c}\text { Yaşlıya Yönelik Olumsuz } \\
\text { Ayrımcıık }\end{array}$ & $30,8 \pm 4,4$ & $29,5 \pm 4,3$ & 0,182 & $30,2 \pm 4,3$ \\
Toplam YATö puanı & $17,2 \pm 3,2$ & $16,7 \pm 3,0$ & 0,472 & $17,0 \pm 3,1$ \\
\hline
\end{tabular}

$\mathrm{p} \dagger$ : Bağımsız gruplarda $\mathrm{t}$ testi. Mean: ortalama, SD: standart sapma

\section{TARTIŞMA ve SONUÇ}

Çalışmamızın sonuçlarına göre; öğrencilerin YATÖ toplam puan ortalaması 82,6 \pm 8,7 puan olup, yaşlı ayrımcılığına ilişkin tutumlarının olumlu olduğu belirlenmiştir. Geriatri stajı yapan öğrencilerin YATÖ toplam puanlarının, yapmayanlara göre daha yüksek olduğu fakat bu farkın istatistiksel olarak anlamlı olmadığı saptanmıştır. YATÖ puanları kadınlarda, şehir merkezinde doğan kişilerde, yaşamının uzun bölümünü köy/kasabada geçirenlerde, kardeş sayısı 3'ün altında olan kişilerde ve 2 ila 4 yıl arasında yaşlılarla birlikte yaşayan kişilerde yüksek bulunmuştur. YATÖ alt boyut puanları açısından geriatri stajı yapan ve yapmayan öğrenciler arasında anlamlı bir farklılık tespit edilmemiştir.

Fizyoterapistler meslek kapsamları gereği farklı bölümle işbirliği halinde çalışmakta olduğundan yaşlı bireylere sundukları hizmet sadece geriatri merkezleri ve huzurevleri ile sınırlı değildir. Fizyoterapistler meslek hayatları boyunca farklı bölümlerde birçok yaşlı bireyi tedavi etmektedir. $\mathrm{Bu}$ nedenle fizyoterapistlerin ve fizyoterapist adaylarının yaşlılara yönelik 
tutumları önemlidir. Yaşlı ayrımcılığına yönelik tutum ve davranışlarla ilgili çalışmalarda, genellikle yaşl1lara yönelik tutumun olumlu veya olumsuz olduğu belirtilmektedir. Sağlik alanında eğitim gören öğrencilere yönelik yapılan çalışmalarda yaşlılara yönelik tutumların genellikle olumlu olduğu görülürken $(1,13,14)$, yaşlılara yönelik tutumların olumsuz olduğunu gösteren çalışmalar da mevcuttur $(15,16)$. Bizim çalışmamızda öğrencilerin yaşlılara yönelik tutumlarının olumlu olduğu belirlenmiştir. Sağlık alanında çalışacak bireylerin YATÖ puanlarının yüksek olması dolayısıyla yaşlılara yönelik tutumlarının olumlu olması arzu edilen bir durumdur. Bu nedenle sağlıkla ilgili bölümlerde eğitim planlaması yapılırken bu durum göz önüne alınmalıdır.

Yaşlı ayrımcılığına ilişkin tutum ve davranışları araştıran çalışmalar genellikle hemşirelik bölümünde yoğunlaşmaktadır $(14,17)$. Bunun yanında sağlıkla ilgili diğer bölümlerde de benzer çalışmalar yapılmıştır $(15,18)$. Yapılan çalışmalarda hemşirelik bölümü öğrencilerinde YATÖ toplam puanlarının genellikle 68-100 puan aralığında $(8,19,20)$, yaşlı bakım öğrencilerinde 72 puan (21), tıp fakültesi öğrencilerinde ise 51 puan olduğu görülmüştür (15). Bizim

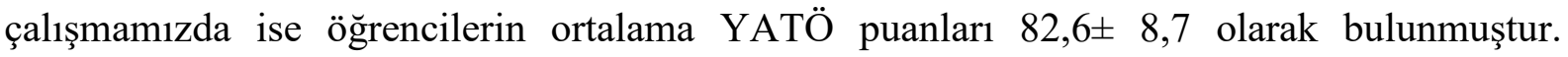
Çalışmamızda YATÖ puanları her ne kadar literatürdeki yayınlarla benzerlik gösterse de bu puanların düşük olduğunu düşünmekteyiz. Çünkü kültürümüzde ebeveynlerle çocuklar arasında yakın bir ilişki bulunmakta ve geleneksel olarak gençlerin yaşı bireylere karşı saygı ve hürmet göstermesi, dolayısıyla yaşlılara karşı tutumlarının daha pozitif olması beklenmektedir (22). Fakat geniş aile yapısının zamanla çekirdek aileye dönüşmesi, kentleşme oranını artması vb. nedenlerle sosyal yapının değişmesi, kültürel yapıdaki değişiklikleri de beraberinde getirmiştir. Bu değişikliklerin yaşlılara yönelik tutumları olumsuz yönde etkilediği düşünülmektedir.

Literatür incelendiğinde cinsiyet, aile yapısı ve doğum yeri gibi değişkenlerin yaşlıya yönelik tutumları etkilediği görülmüştür. Bazı çalışmalarda cinsiyetin tutumları etkilediği (22), bazılarında ise etkilemediği (18); bazı çalışmalarda kız öğrencilerin tutumlarının erkeklere göre daha olumlu bulunduğu (23), bazılarında ise erkek öğrencilerin tutumlarının daha olumlu bulunduğu belirtilmektedir (24). Bizim çalışmamızda ise kadın öğrencilerin YATÖ puanları erkeklere oranla yüksek bulunmuştur. Bu farklılıkları bazı yazarlar kadınların bakım verici rollerinde dayandırmakta, bazı yazarlar ise farklılığın annelik rolünden ve içgüdüsellikten kaynaklandığını belirtmektedir $(15,18)$. Bu yorumlara ek olarak sosyokültürel özelliklerin de bu farklılığa yol açabileceğini düşünmekteyiz. 
Yaşlılara yönelik tutumu etkileyen etmenlerden biri de mezuniyet sonrası yaşlılarla çalışma isteğidir. Ayoğlu ve arkadaşlarının çalışmasında öğrencilerin\% 66,6'sının mezuniyet sonrası yaşlılarla çalışmak istediği belirtilmiştir (25). Darling ve arkadaşlarının çalışmasında ise öğrencilerin \%55'i mezuniyet sonrasında yaşlılarla çalışmaya istekli olduklarını ifade etmişlerdir (26). Bizim çalışmamızda ise öğrencilerin \%53,3’ü mezuniyet sonrası yaşlılarla çalışmak istediğini belirtmiş ve bunun sebebi olarak da 'Yaşlıların bedensel ve psikolojik desteğe daha çok ihtiyaç duyması' 'nı göstermişlerdir. Yaşlılarla çalışmak istemeyen grup ise bunun sebebinin 'Uzun süre yaşlılarla çalışmanın tükenmişliğe sebep olması" olduğunu ifade etmiştir.

Araştırmamızın sonuçları Süleyman Demirel Üniversitesindeki fizyoterapist adaylarının yaşlılara yönelik tutumlarının olumlu olduğu ve geriatri alanında staj yapmanın yaşlı ayrımcılığına ilişkin tutumları olumlu anlamda etkilediğini göstermektedir. Bu bağlamda gelecekte yaşı bireylere hizmet verecek fizyoterpist adaylarının yaşlılara yönelik tutumlarının olumlu olmasının bu hizmetin kalitesini arttıracağı düşünülmektedir.

\section{KAYNAKLAR}

1. Yilmaz F, Çağlayan Ç. Yaşlılarda sağlıklı yaşam tarzının yaşam kalitesi üzerine etkileri. Türk Aile Hek Derg. 2016;20(4):129-40.

2. Alvarenga GM, Charkovski SA, Gamba HR. The influence of inspiratory muscle training combined with the Pilates method on lung function in elderly women: A randomized controlled trial. Clinics. 2018;73:e356

3. Sarı D, Baysal E, Taşkıran N, Acar E, Akyıl RÇ. Hemşirelik Öğrencilerinin Yaşlı Bireylere Yönelik Tutumları ve Empatik Yaklaşım Becerileri. SDU Journal of Health Science Institute/SDÜ Saglik Bilimleri Enstitüsü Dergisi. 2019; 10(2).

4. Yilmaz Vefikuluçay D, Terzioğlu F. Development and psychometric evaluation of ageism attitude scale among the university students. Turkish J Geriatr. 2011;14(3):258-68.

5. Çilingiroğlu N.Demirel S. Aging and ageism. Turkish J Geriatr. 2004;7(4):225-30.

6. Bulut E, Cilingir D. Ageism and reflections of nursing care. TAF Prev Med Bull. 2016;15(5):446.

7. Vefikuluçay, D. Terzioğlu F. Ageism and nursing: review. J Nurs. 2010;2(2):137-44.

8. Altay B, Aydın T. Evaluation of attitudes of nursing students Towards ageism. Hemşirelikte Eğitim ve Araştırma Derg. 2015;12(1):11-8.

9. Hanson RM. "Is elderly care affected by nurse attitudes?" A systematic review. Br J Nurs. 2014;23(4):225-9.

10. Yen CH, Liao WC, Chen YR, Kao MC, Lee MC, Wang CC. A Chinese version of Kogan's Attitude toward Older People Scale: Reliability and validity assessment. Int J Nurs Stud. 2009;46(1):38-44. 
11. Hatton AL, Mandrusiak A. A Single Clinical Experience in a Nursing Home Improves Physiotherapy Students' Attitudes Towards, and Confidence to Communicate With, Older People. Phys Occup Ther Geriatr. 2018;36(2-3):168-78.

12. Karadağ E, İnkaya V, Karatay G. Hemşirelik öğrencilerinin yaşlı ayrımcılığına ilişkin tutumları. Ege Üniversitesi Hemşirelik Fakültesi Dergisi 28 (2) : 31-40, 2012

13. Yılmaz E. Hemşirelik Öğrencilerinin Yaşlı Ayrımcılığına İlişkin Tutumları. Maltepe Üniversitesi Hemşirelik Bilim ve Sanatı Dergisi. 2010;3(2):35-53.

14. Çilingir D, Bulut E. Hemşirelik Bölümü Öğrencilerinin Yaşlı Ayrımcılığına İlişkin Tutumları . DEUHFED. 2017;10(3):137-43.

15. Köse G, Ayhan H, Taştan S, İyigun E, Açıkel C, Hatipoglu S. Determination of the attitudes of students from different department in the field of health on the discrimination against the elders. Gülhane Med J. 2015;57(2):145.

16. Zhou LY. What college students know about older adults: A cross-cultural qualitative study. Educ Gerontol. 2007;33(10):811-31.

17. Karahan FS, Hamarta E, Karahan AY. An anthropological contribution about ageism: Attitudes of elder care and nursing students in Turkey towards ageism. Stud Ethno-Medicine. 2016;10(1):59-64.

18. Ünalan D, Soyuer F, Elmalı F. The attitudes towards elderly by the personnel of geriatric care centres. Kafkas J Med Sci. 2012;2(3):115-20.

19. Özer ZC, Terkeş N. Evaluation of Nursing Student's Attitudes towards Ageism in Turkey. Procedia - Soc Behav Sci. 2014;116(90242):2512-5.

20. Kalaycı I, Yazıcı SÖ, Özkul M. Attitudes ofMedical Staff and Students Towards the Elderly. Adnan Menderes Üniversitesi Sağlık Bilim Fakültesi Derg. 2017;2(1):21-30.

21. Yazıcı SÖ, Kalaycı I, Kaya E, Tekin A. Attitudes of Students Studying In Health Related Departments towards the Elderly. Gaziantep Univ J Soc Sci. 2016;15(24217):601-14.

22. Yildiz A, Usta YY, Demir Y, Yo M. Nursing students ' attitudes toward ageism in Turkey. Arch Gerontol Geriatr. 2012;54:90-3.

23. Güven ŞD, Ucakan Muz G . Üniversite öğrencilerinin yaşlı ayrımcılığına ilişkin tutumları ve bu tutumların bazı değişkenlerle ilişkisi. Anadolu Hemşirelik ve Sağlık Bilim Derg. 2012;15(2):99-105.

24. Mcconatha JT, Hayta V, Rieser-danner L, Mcconatha D, Polat TS, Tahmaseb J, et al. Turkısh and US . attitudes toward aging. Educ Gerontol. 2004;30:169-83.

25. Ayoğlu FN, Kulakçı H, Ayyıldız TK, Aslan GK, Veren F. Attitudes of Turkish Nursing and Medical Students Toward Elderly People. J Transcult Nurs. 2014;25(3):241-8.

26. Darling R, Sendir M, Atav S, Buyukyilmaz F. Undergraduate nursing students and the elderly: An assessment of attitudes in a Turkish university. Gerontol Geriatr Educ. 2018;39(3):283-94. 